\title{
Radiological Investigation in the Management of Uveitis
}

\author{
M. W. AUSTIN and L. G. CLEARKIN \\ Liverpool
}

\begin{abstract}
Summary:
Patients suffering from Uveitis often undergo radiological investigation in order to detect underlying sarcoidosis or ankylosing spondylitis. We reviewed the results of $\mathrm{X}$-rays performed in this hospital over a four year period in order to determine the efficiency of such screening. Our results suggest that radiological investigation has little role in the management of patients with Uveitis.
\end{abstract}

The prevelance of uveitis in patients suffering from sarcoidosis or ankylosing spondylitis is high at $15-25 \%^{1,2,3.4}$ and $20 \%^{1}$ respectively. In order to detect these conditions, chest and sacro-iliac joint $\mathrm{x}$-rays are routinely carried out in patients with uveitis in this hospital. Radiological examination is an effective method of investigating patients who may have these conditions, but the efficiency of such screening in uveitis patients is uncertain. We have reviewed the results of radiological investigations carried out on a group of such patients and also evaluated the therapeutic impact, in terms of disability and requirement for treatment in those identified.

\section{Patients and Methods}

The X-ray department records of St. Paul's Eye Hospital, Liverpool for the period 1st January 1983 to 31st December 1986 were examined retrospectively. The reports and case notes of all patients with uveitis having $\mathrm{x}$-ray findings suggestive of sarcoidosis or ankylosing spondylitis were obtained. Details of age, sex, category of uveitis, previous and subsequent ophthalmic history and systemic symptoms pre-dating radiological diagnosis were recorded. A questionnaire was sent to each patient's general practitioner requesting details of therapy and disability.

\begin{abstract}
Results
During the above period 782 patients, 394 male (age 2-85 years; mean 42.6 yrs) and 388 female (age 11-87 yrs; mean 46.4yrs) were investigated radiologically during an attack of uveitis (Table).
\end{abstract}

\section{Chest Radiography}

Seven hundred and fifty-eight patients (375 male, 383 female) were investigated; four $(0.052 \%$; 3 male age $33-36$, and 1 female age 42) were subsequently diagnosed as having sarcoidosis. Questionnaire replies were received in all cases. Three patients required no treatment and one was taking oral pre: dnisolone to control posterior uveitis.

Three patients with previously diagnosed sarcoidosis had normal chest $\mathrm{x}$-rays, 14 chest $\mathrm{x}$-rays showed miscellaneous non-pathological findings

\section{Sacro-iliac Radiography}

Five hundred and twenty-five patients (304 male, 221 female) were investigated; 76 (14.5\% ; 50 males 26 females) had radiological evidence of sacro-iliitis. Questionnaire replies were received from the General Practitioners of 69 patients $(91 \%)$. Ten patients (5 male age 16-47 yrs and 5 female age 25$71 \mathrm{yrs})$ required treatment, of whom seven 
Table Details of category of uveitis in each group.

\begin{tabular}{lccc}
\hline $\begin{array}{l}\text { Category } \\
\text { of uveitis }\end{array}$ & $\begin{array}{c}\text { All patients } \\
n=782\end{array}$ & $\begin{array}{c}\text { Sarcoidosis } \\
\mathrm{n}=4\end{array}$ & $\begin{array}{c}\text { Sacro-iliitis } \\
\mathrm{n}=76\end{array}$ \\
\hline Anterior & 562 & 2 & 71 \\
Pars planitis & 11 & 0 & 0 \\
Posterior & 22 & 0 & 0 \\
Pan-uveitis & 12 & 0 & 2 \\
Retinal vasculitis & 7 & 0 & 0 \\
Unspecified & 168 & & 3 \\
\hline
\end{tabular}

had recurrent episodes of uveitis and seven had typical symptoms of sacro-iliitis (low back pain, morning stiffness, symptomatic improvement with mobilisation). All were receiving non-steroidal anti-inflammatory drugs, two patients having additional physiotherapy. Six patients were judged as having moderate disability, and two severe. No other diagnoses were made as a result of sacro-iliac radiography.

\section{Discussion}

The rate of diagnosis of sarcoidosis was low, at less than $1 \%$. The therapeutic impact was also low with no patient requiring treatment for systemic disease. Although about $90 \%$ of patients with sarcoidosis at some stage have abnormal chest $\mathrm{x}$-rays ${ }^{4}$, only $4 \%$ are thought to present with eye signs ${ }^{5}$. Chest $x$-ray examination is unlikely to be rewarding unless the overall clinical picture suggests the diagnosis of sarcoidosis.

Of 525 patients investigated, 76 (14.5\%) had evidence of sacro-iliitis. Data were available regarding treatment and disability for 69 patients of whom 10 were receiving therapy. Taking into account the remaining seven the maximum number needing treatment is 17 or $3.2 \%$ of those screened.

Although uveitis would seem to be a not infrequent presenting feature of ankylosing spondylitis, less than a quarter of patients identified required treatment. This low therapeutic impact is a reflection of the range of disease in ankylosing spondylitis, only a minority being severely affected. As treatment for the majority is directed at relief of pain and maintenance of posture it may be argued that there is little benefit from presymptomatic diagnosis, especially as this requires gonadal irradiation.

In the light of these results we suggest that patients with uveitis do not constitute a population in whom routine radiological screening may be effectively performed ${ }^{6}$. Radiological investigation of patients with uveitis should be limited to those exhibiting other features of systemic disease.

\section{References;}

${ }^{1}$ Perkins ES: The aetiology and treatment of uveitis Trans Ophthalmol Soc UK 1958; 78: 511-22

${ }^{2}$ Perkins ES: Uveitis survey at the Institute of Ophthalmology (in) Bronson SB, Gamble CN, Goodner EK, O'Connor GR:(eds) Clinical methods in Uveitis, St Louis; Mosby; $1968 ; 58-65$

${ }^{3}$ Saari M, Miattien R, Alenko H: Uveitis: a report of a 20 year survey in Northern Finland. Can J Ophthalmol 1975; 10: 356-60

${ }^{4}$ Silzbach LE, James DG, Neville E et al: Course and prognosis of Sarcoidosis around the world. Am J Med 1974: 57; 847-52

${ }^{5}$ British Thoracic and Tuberculosis Association. Geographical variation in the incidence of Sarcoidosis in Great Britain; a comparative study of four areas. Tubercule, $1969 ; \mathbf{5 0} ; 211$ 31

${ }^{6}$ Roberts CJ: Epidemiology for Clinicans. Tunbridge Wells. Pitman Medical: 1977. 86-89. 